\title{
RESEARCH OF REPARATIVE MECHANISMS IN THE OPTIC NERVE IN TOXIC NEUROPATHY CAUSED BY Cr (VI)
}

\author{
Olena Kuzenko ${ }^{1}$, Yuri Demin ${ }^{2}$, Yevhen Kuzenko ${ }^{3}$ \\ ${ }^{1}$ Department of Ophthalmology, Kharkiv Medical Academy of Postgraduate Education, Kharkiv, Ukraine \\ logvinenok26@gmail.com \\ ${ }^{2}$ Department of Ophthalmology, Kharkiv Medical Academy of Postgraduate Education, Kharkiv, Ukraine \\ deminprof@gmail.com \\ ${ }^{3}$ Department of Pathology, Medical Institute of Sumy State University, Sumy, Ukraine \\ yevhen.kuzenko@gmail.com
}

\begin{tabular}{l} 
A R T I L E IN F O \\
\hline Article history: \\
Received date 17.11 .2019 \\
Accepted date 18.12 .2020 \\
Published date 30.12 .2020 \\
Section: \\
Practical medicine \\
D O I \\
10.21303/2313-8416.2020.001549 \\
K E Y W O R D S \\
hromium-induced neuropathy \\
oxidative stress \\
heat shock proteins \\
global pollution
\end{tabular}

ABSTRACT

Intoxication lesions of the optic nerve (toxic optic neuropathy, TON) most often occur under the influence of exogenous factors, including heavy metals. Cell survival under stress have involves heat shock proteins (HSPs).

The aim of the research. To assess the optic nerve's immunoreactivity to heat shock proteins of the HSP70 and HSP90 $\alpha$ families and reveal its relationship with the severity of morphological changes in toxic optic neuropathy caused by $\mathrm{Cr}$ (VI).

Materials and methods. The study was conducted on 48 mature male rats. The experimental groups were given to drink water with $\mathrm{Cr}(\mathrm{VI})$ for 20, 40 and 60 days. This type of water is typical for the water basins in the northern districts of the Sumy region. Optic nerves changes under the influence of $\mathrm{Cr}(\mathrm{VI})$ have investigated by the morphometric method. Neuroglial cells and capillary endothelial cells were assessed by immunohistochemistry by HSP70 $\alpha$ and HSP90 expression for intensity and spatial distribution.

Results. The data analysis revealed that $\mathrm{Cr}$ (VI) has a neurotoxic effect on the optic nerve with the development of edema, which is manifested by the thickening of nerve fibers. The dynamics of HSP70 immunoexpression in the endothelium of the optic nerve capillaries of rats on 20 and 40 experimental days was characterized by stable values and was 1.5 times higher than the control. The maximum number of positively stained cells for the HSP70 marker was detected in endothelial cells of the microvasculature for 60 days $82.44 \pm 12.42 \%$. HSP70 levels in neuroglia cells of optic nerve have decreased on day 40 $(55.66 \pm 11.56 \%, p=0.05)$ and lower than the control (70.44 $\pm 4.81 \%$.) group. Optic nerve capillaries was highest immunoactivity on HSP90 in group II endothelial cells $-51.22 \pm 14.57 \%$ $(p=0.05)$. The activity of HSP90 $\alpha$ protein in optic neuroglia cells was characterized by a gradual increase in the duration of the experiment and was higher by $12.4 \%$ in experimental group III ( $81.77 \pm 21.67 \%)$ compared with control (71.66 $\pm 4.95 \%)$.

Conclusions. Our study provides an insight into the significant difference in the immunoreactivity of heat shock proteins of the HSP70 and HSP90 $\alpha$ families in neuroglia and endothelial cells of the optic nerve capillaries under the influence of $\mathrm{Cr}(\mathrm{VI})$.

The results obtained suggest that $\mathrm{Cr}$ (VI) has a neurotoxic effect on the optic nerve with the development of edema, which is manifested by the thickening of nerve fibers. A comparison of the dynamics of the development of the dystrophic process in the optic nerve with the results of the immunohistochemical analysis showed, that an increase in the thickness of nerve fibers is accompanied by an increase in immunoreactive neuroglial cells (HSP90 $\alpha$ ) and endothelial cells (HSP70).

(C) The Author(s) 2020. This is an open access article under the CC BY license http://creativecommons.org/licenses/by/4.0).

\section{Introduction}

\section{1. The object of the research}

Heat shock proteins (HSP70 and HSP90 $\alpha$ ) expression during experimental toxic optical neuropathy induced by $\mathrm{Cr}(\mathrm{VI})$.

\section{2. Problem description}

Intoxication lesions of the optic nerve (toxic optic neuropathy, TON) most often occur under the influence of exogenous factors [1,2], including heavy metals [3]. As the process progresses, 
develop acute or chronic progressive death of retinal ganglion cells and their axons, which leads to morphological changes.

Over the past few decades, emissions of pollutants into the environment have increased significantly due to rapid industrialization, urbanization, and overuse of agricultural fertilizers $[4,5]$. One of the 14 most toxic heavy metals that pollute the environment, according to the Environmental Protection Agency India, is hexavalent chromium (Cr (VI)), due to its widespread use in the industry [6]. The lack of proper control over the disposal of $\mathrm{Cr}$ (VI) waste leads to an increase in the level of $\mathrm{Cr}$ (VI) in soil, water, air, polluting the environment $[6,7]$. The most common routes of exposure to chromium through these media are ingestion, inhalation, and dermal contact with soil, water, or particulates in the air contaminated with chromium.

Together with cobalt, hexavalent chromium compounds are widely used in medicine to create metal components of endoprostheses. A significant disadvantage of these prostheses is the formation of submicroscopic friction products $[8,9]$, toxic to the body, due to the release of heavy metal ions, particularly cobalt and chromium [10], due to implant wear and corrosion [11, 12]. A number of works carried out worldwide speak about the pathological influence of ions of cobalt and chromium on an organism $[13,14]$. Of interest are ophthalmic complications, of which, to date, only isolated cases have been published in the medical literature $[15,16]$. According to the Garcia M. D. and others, the $\mathrm{Cr}(\mathrm{VI})$ toxic role have been remains unclear [17].

Data from the literature do not provide a complete answer to the question of the points of application and the main mechanisms of development of disorders in the optic nerve due to the entry of hexavalent chromium into the body.

\section{3. Suggested solution to the problem}

Resisting apoptosis is unthinkable without heat shock proteins (HSPs) due to their participation in a wide range of stress conditions, including pollution of the environment with heavy metals $[18,19]$. The most studied of them are ATP-dependent chaperones with molecular weights from 40 to $105 \mathrm{kDa}$. These include the well-known chaperones of the 70 and $90 \mathrm{kDa}$ families. The main functions of folding, refolding, elimination of irreversibly denatured protein conglomerates, or accompaniment into lysosomes (chaperone function for other proteins) to ensure homeostasis, growth processes and cell differentiation [20,21].

In the intact retina of amphibians, the expression of HSP70 was observed mainly in the outer layers of the retina, and HSP90 - in the inner, mostly in Mueller cells and optic nerve, while ensuring the adaptive stability of its intracellular structures [22]. On immunohistochemical, HSP70 is almost not expressed in neurons, but Tytell M. and co-authors first found that this polypeptide is secreted by neuroglia cells and transported to nerve axons, thereby performing a cytoprotective function, being in adjacent cells [23].

The main aim of the work. To assess the optic nerve's immunoreactivity to heat shock proteins of the HSP70 and HSP90 $\alpha$ families and reveal its relationship with the severity of morphological changes in toxic optic neuropathy caused by $\mathrm{Cr}(\mathrm{VI})$.

\section{Materials and methods}

The rats have been kept in vivarium conditions from February to March 2018 (the vivarium of Medical Institute of Sumy State University). The study was carried out on white, unpedigreed male rats weighing $180-200 \mathrm{~g}$ at four months $(\mathrm{n}=48)$. The conditions of the Declaration of Helsinki (General Assembly of the World Medical Association, 2008), norms and principles of the European Convention for the Protection of Vertebrate Animals used for research and other scientific purposes were strictly observed.

\section{1. Experimental procedures}

Toxic optical neuropathy in animals was simulated by adding $\mathrm{K}_{2} \mathrm{Cr}_{2} \mathrm{O}_{7}$ to ordinary drinking water at a dose of $0.02 \mathrm{~mol} / \mathrm{l}$, which is most typical for Ukraine's contaminated regions.

For studying the dynamics of changes in the optic nerve, the experimental animals were divided into three groups, depending on the duration of taking ordinary water enriched with an increased concentration of $\mathrm{Cr}(\mathrm{VI})$. - Group I ( $n=8)$ - 20 days from the beginning of the experiment, 
Group II $(n=8)-40$ days and Group III $(n=8)-60$ days, respectively. Each experimental group contained 8 control rats that drink plain water.

After the experiment's expiry, the animals were decapitated under ether anesthesia and their eyes were enucleated.

For histomorphometric examination of the optic nerve, laboratory rats were placed in a vessel where the organ was fixed in a $10 \%$ buffered solution of neutral formalin for 24 hours. Then dehydration of the organ was performed. On a rotary microtome, serial paraffin sections of the optic nerve $5 \times 10^{-6} \mathrm{~m}$ thick were obtained, which were placed on a glass slide and stained with hematoxylin and eosin.

The obtained preparations were examined, photographed and measured using a microscope "Carl Zeiss Primo Star" (Germany) (binoculars $\times 10$, lenses $\times 10, \times 40$ ) with a digital camera "Zeiss AxioCam ERC 5s" (Germany) and software package output image system and calculation of "ZEN 2 (blue edition)" (Germany).

Morphometric measurements were performed using the Digimazer program. All micrometric indicators are presented in units of length according to the International System of Units $10^{-6} \mathrm{~m}(\mu \mathrm{m})$.

For immunohistochemical study, truncated serial samples of the optic nerve were applied to glasses with high adhesiveness SuperFrost (Thermo Scientific, USA). The slides together with the material were placed in a thermostat, where they were dried at $37{ }^{\circ} \mathrm{C}$ for 18 hours. The obtained samples were subjected to dehydration after dewaxing. Unmasking was performed in citrate buffer $\left(\mathrm{pH}\right.$ 6.0) at a temperature of $95-98^{\circ} \mathrm{C}$. The UltraVision Quanto Detection System HRP Polymer (Thermo scientific, USA) was used to visualize the primary antibodies. Blocking of endogenous peroxidase was performed with $3 \%$ hydrogen peroxide solution. As a chromogen used diaminobenzidine (Thermo Scientific, USA). After the immunohistochemical reaction, sections were stained with Mayer's hematoxylin for better differentiation of tissue structures. Branches of the optic nerve were processed using polyclonal antibodies in a 1:200 dilution to HSP90 $\alpha$ and Hsp70 protein (Thermo Scientific and Abcam, USA).

Evaluation of the immunohistochemical reaction results was performed by calculating the area of expression (the ratio of the area of immunopositive cells to the total area of all cells expressed as a percentage) of cell elements. The reaction was considered positive in the presence of positively stained cells more than $1 \%$ in 10 fields of view at a magnification of the microscope $\times 400$.

The images were captured by a computer-assisted digital camera, "Zeiss AxioCam ERc 5s", connected to the microscope.

All statistical analyses were performed using the Statistical Package for Social Science program (SPSS for Windows, version 15.0, SPSS Inc., Chicago, IL, USA). Determining the reliability of differences was performed using Student's $t$-test $(t)$. The value of $P<0.05$ was considered as significant.

\section{Results}

The results of the immunohistochemical examination of optic nerve samples of experimental rats of all groups showed different expression of HSP70 (Fig. 1) and HSP90 $\alpha$ (Fig. 2) in neuroglia cells and capillary endothelial cells depending on the duration of the experiment (Table 1).

\section{Table 1}

The content of HSP70 and HSP90 proteins in neuroglia and endothelial cells of the optic nerve capillaries of experimental animals under the influence of hexavalent chromium $(\mathrm{Cr}(\mathrm{VI})), \%,(M \pm m ; n=8)$

\begin{tabular}{ccccc}
\hline Animal groups & Type of cells & HSP70 & HSP90 $\boldsymbol{\alpha}$ & The size of the nerve fiber, $\boldsymbol{\mu m}$ \\
\hline \multirow{2}{*}{ Control } & Endothelial cells & $16.11 \pm 12.93$ & $15.55 \pm 11.57$ & $10.4 \pm 2.1$ \\
& Neuroglia & $70.44 \pm 4.81$ & $71.66 \pm 4.95$ & $11.3 \pm 3.2$ \\
Group I & Endothelial cells & $25.33 \pm 12.49$ & $12.77 \pm 8.83$ & $13.4 \pm 2.1$ \\
(20 days) & Neuroglia & $65.88 \pm 10.36$ & $76.33 \pm 10.80$ & \\
Group II & Endothelial cells & $24.44 \pm 11.57$ & $51.22 \pm 14.57^{*}$ & $15.7 \pm 1.3$ \\
(40 days) & Neuroglia & $55.66 \pm 11.56^{*}$ & $79.11 \pm 20.41$ & $18.33 \pm 12.93$ \\
Group III & Endothelial cells & $82.44 \pm 12.42$ & $81.77 \pm 21.67$ &
\end{tabular}

Note: *-statistical significance was set at $p=0.05$ 
The control group of rats had a small number of HSP70 and HSP90 $\alpha$ positive endothelial cells in the capillaries; their number was statistically insignificant. Simultaneously, in the optic neuroglia cells observed a high level of positive cells HSP70, HSP90 $\alpha$ at $p<0.05$.

The dynamics of HSP70 immunoexpression in the endothelium of the optic nerve capillaries of rats of I and II experimental groups was characterized by stable values and was 1.5 times higher than the control. The maximum number of positively stained cells for the HSP70 marker was detected in endothelial cells of the microvasculature for 60 days $(82.44 \pm 12.42 \%)$, which was regarded as a strongly positive reaction. Optic nerve neuroglia cells of all study groups expressed HSP70 in almost the same amount according to the control, except for the experimental group II, where this protein's activity was equal to $-55.66 \pm 11.56 \%$ and was lower than the control $-70.44 \pm 4.81 \%$.
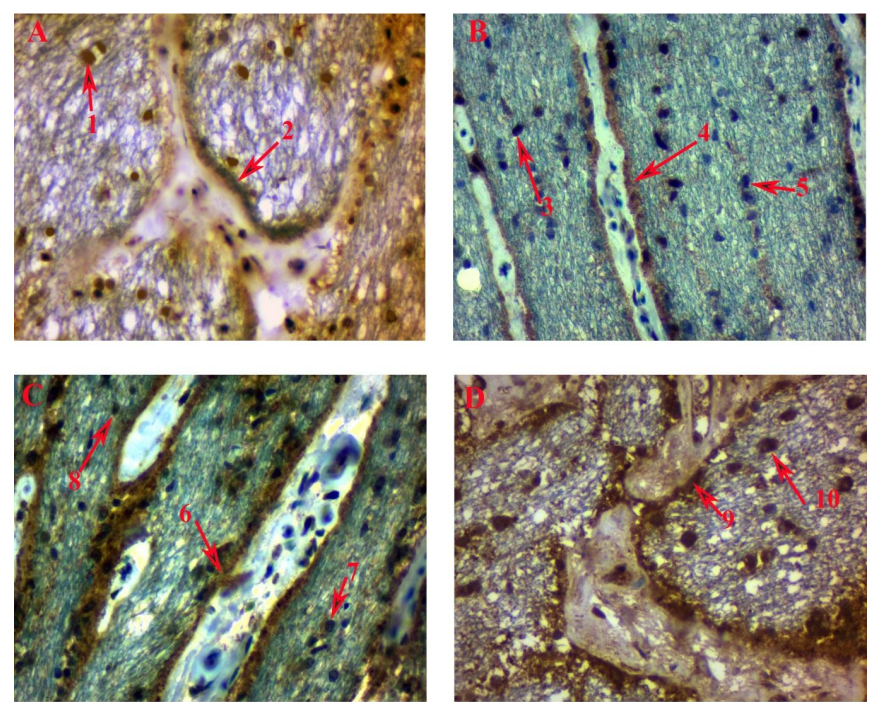

Fig. 1. Longitudinal section of the intracranial optic nerve of rats exposed to hexavalent chromium (Cr (VI)) at different time intervals. Immunohistochemical study of HSP70 expression: magnification $\times 400$ : $\mathrm{A}-$ Control group: 1 - astrocytes; 2 - endothelium of the capillaries of the optic nerve; B - I experimental group (20 days): 3 - HSP70 - negative astrocytes; 4 - capillary endothelium with moderate expression of HSP70;

5 - HSP70 - positive cytoplasmic reaction of astrocytes; C - II experimental group (40 days): 6 - capillary endothelium with moderate expression of HSP70; 7 - HSP70 - positive cytoplasmic reaction of astrocytes; 8 - HSP70 negative astrocytes; D - III experimental group (60 days): 9 - capillary endothelium with moderate expression of HSP70; 10 - HSP70 positive cytoplasmic reaction of astrocytes

Regarding the immunohistochemical activity of HSP90 $\alpha$ in the endothelial cells of the optic nerve capillaries, it was highest in the II experimental group and was equal to $51.22 \pm 14.57 \%$, followed by a sharp decrease to $18.33 \pm 12.93 \%$ in the III group of the study and almost approaching it to the level of control $-15.55 \pm 11.57 \%$ at $p<0.05$. The activity of HSP90 $\alpha$ protein in optic neuroglia cells was characterized by a gradual increase in the duration of the experiment and was higher by $12,4 \%$ in experimental group III $(81.77 \pm 21.67 \%)$ compared with control $(71.66 \pm 4.95 \%)$.

The results of morphometric analysis indicate the presence of edema of the optic nerve, which is reflected in an increase in the thickness of nerve fibers (Table 1). In some parts of the optic nerve revealed the phenomena of focal stratification with the phenomena of precellular edema.

As a result of the correlation analysis, we found an average positive relationship between the thickness of the optic nerve fiber and the expression of HSP70 in capillary endotheliocytes $-r=0.88$, at $p=0.01$. Also, a strong positive correlation was found between HSP90 $\alpha$ in neuroglial cells and the thickness of the nerve fiber $-r=0.94$, at $p=0.05$. 

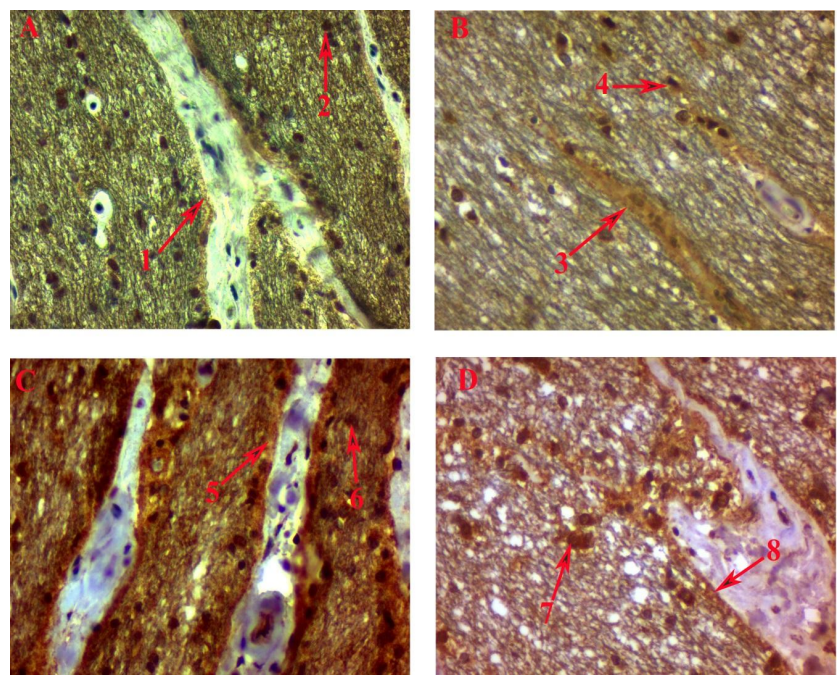

Fig. 2. Longitudinal section of the intracranial optic nerve of rats exposed to hexavalent chromium $(\mathrm{Cr}$ (VI)) at different time intervals. Immunohistochemical study of HSP90 $\alpha$ expression: magnification $\times 400$. A - Control group: 1 - capillary endothelium with weak expression of HSP90 $\alpha$;

2 - HSP90 $\alpha$ - positive cytoplasmic reaction of astrocytes; B - I experimental group (20 days): 3 - endothelial reaction of HSP90 $\alpha ; 4$ - positive cytoplasmic and nuclear reaction of HSP90 $\alpha$ of astrocytes; C - II experimental group (40 days): 5 - significant endothelial expression of HSP90 $\alpha$ in capillaries; 6 - positive cytoplasmic, and nuclear reaction of HSP90 $\alpha$ astrocytes; D - III experimental

group (60 days): 7 - endothelial expression of HSP90 $\alpha$ with dyscirculatory changes; 8 - positive cytoplasmic and nuclear reaction of $\mathrm{HSP} 90 \alpha$ astrocytes against edematous changes

\section{Discussion}

For the first time, our study describes the features of the immunoexpression of heat shock proteins of the families: HSP70 and HSP90 $\alpha$ in optic neuropathy associated with $\mathrm{Cr}$ (VI).

Some researchers believe that oxidative stress with the formation of ROS and activation of apoptosis resulting from mitochondrial dysfunction is a key link in the degeneration of retinal ganglion cells and their axons in the optic nerve [24, 25]. According to the literature, $\mathrm{Cr}$ (VI) enhances the accumulation of ROS by blocking complex I of the mitochondrial respiratory chain [26], and also reduces the activity of antioxidant enzymes [27]. Cr (VI), like other cationic metals, penetrates the outer mitochondrial membrane through the mechanism of molecular mimicry [28, 29]. Due to the high content of lipids with polyunsaturated fatty acids, brain mitochondria membranes are more sensitive to free radical oxidation under pathological conditions [30].

Heat shock proteins HSP70/HSP90 resist apoptosis, which in the early stages are able to reduce the consequences of free radical damage to mitochondrial membranes. It is HSP70, and according to other data, HSP90 [31], binds to Apaf-1, blocking the formation of the Apaf-1 - cytochrome $\mathrm{C}$ complex in the cytoplasm and disrupting the Apaf-1 bond with procaspase-9, that is, disrupting the very process of apoptosome formation [32]. It should be recalled that ROS overproduction promotes activation of the internal molecular pathway of cell apoptosis, which is regulated in mitochondria [33]. Activation of the internal pathway of apoptosis leads to an increase in the permeability of the mitochondrial membrane due to the opening of the pores and the release of cytochrome $\mathrm{C}$ into the cytoplasm, which binds to the activating factor of apoptotic protease - (Apaf-1), which leads to the formation of an apoptosome. Which, in turn, mediates conformational changes and activation of the initiator caspase -9 . As a result, activated caspase -9 triggers the caspase cascade of programmed cell death via procaspases 3 and 7 [34].

In our study, we observed a decrease in the chaperone activity of HSP70 in optic neuroglia cells already in experimental group I. These results can be partially explained by previous studies, which claim that $\mathrm{Cr}$ (VI) activates caspase-3, thereby inducing ROS-dependent decreases in HSP70 and HSP90 [26]. However, as can be seen from our experimental results, the expression of HSP90 in glial cells, on the contrary, moderately increased and reached a peak in experimental group III, 
which only partially coincides with previous studies. A simple interpretation of this is that overexpression of heat shock proteins is part of the cellular stress response and is mainly caused by the heat shock factor (HSF) [35]. Under non-stress conditions, HSF-1 is found in the cytoplasm as an inactive monomer in a complex with HSP90. When a cell is exposed to stress, HSF-1 trimerization occurs, followed by its entry into the nucleus, where it interacts with transcription elements and triggers the process of HSP 90 gene expression [36]. At the same time, the level of other heat shock proteins, including HSP70, remains low. This fact we can explain as the competition of HSPs for binding to HSF-1. In support of this, Fei Dou and coauthors [37] found increased expression of Hsp70 in the primary culture of neurons in the rat embryonic brain (E17), upon administration of an inhibitor of HSP 90, explaining this by the release of heat shock factor 1 (HSF1) from the complex with Hsp90 [38]. Termination of the harmful stimulus leads to rapid deactivation of HSF-1 and return to an inactive form. And in general, the described changes confirm the mechanism of autoregulation of heat shock protein synthesis according to the feedback principle [39].

In addition, the protective mechanism of HSP90 $\alpha$ is also associated with the activation of cellular signalling pathways for key proteins for which it is a chaperone [40]. Induction of HSP90 $\alpha$ has been reported to increase cell survival under oxidative stress caused by pollutants, incl. and heavy metals by activating signalling pathways such as JAK-STAT, ERK 1/2, PI3K/Akt, Bcl-2 and NF- $\kappa B$ [41]. Activated MAP kinase, associated with the trk downstream signalling cascade, was found to coimmunoprecipitated with optic nerve HSP90, suggesting that HSP90 may be utilized in retrograde transport of the secondary messengers associated with neurotrophin signalling. HSP90 can thus be hypothesized to play a role in bidirectional RGC axonal protein transport [42].

We found an opposite picture in the capillary endothelium. Namely, overexpression of HSP70 with prolongation of the experiment time, which, as we hypothesize, is caused to maintain the integrity of the blood-brain barrier under stressful conditions. Namely, overexpression of HSP70 with prolongation of the experiment time, which, as we hypothesize, is caused to maintain the integrity of the bloodbrain barrier under stressful conditions. We came to this conclusion based on its functions. In addition to blocking the caspase-dependent apoptosis pathway mentioned above, Hsp70 can directly bind the apoptosis-inducing factor (AIF), thereby preventing the caspase-independent apoptosis pathway [43]. The mechanism for triggering apoptosis by AIF is the activation of an endonuclease that cleaves nuclear DNA [44]. Kondrikov D. and others have shown that increased expression of Hsp70 under conditions of hyperoxia protects endothelial cells by inhibiting the AIF-dependent pathway of apoptosis [45]. The current result of our study is consistent with the conclusion of R. R. Shivers and co-authors [46], who demonstrated the in vitro induction of HSP70, HSP90 and HSP100 in endothelial cells of the brain microvessels in response to heat shock. They also notice - inhibition of further tight junction assembly and the disappearance and/or disassembly of tight junctions in primary cultures of bovine brain microvessel endothelial cells. It should be noted that the endothelial cells of the microvessels of the brain, together with astrocytes and pericytes, form both the blood-brain and internal blood-retinal barriers, and a violation of the relationship between them can lead to an increase in the permeability of these barriers for macromolecules and fluid from the blood to the retina and optic nerve [47].

More recently, it has been reported that mitochondria play a key role in maintaining the integrity of the blood-brain barrier (BBB) in vitro. Immunocytochemical analysis revealed that the normally well-defined, linear cell-cell junctions were disrupted when oxidative phosphorylation was inhibited by mitochondrial inhibitors [48]. It has long been suggested that mitochondrial dysfunction is associated with developing neurodegenerative diseases [49, 50].

Study limitation. Our study were limited by study of optic nerve heat shock proteins expression (HSP70, HSP90 $\alpha$ ) under the influence $\mathrm{Cr}(\mathrm{VI})$.

Prospects for further research. In the future, it is necessary to experimentally investigate and determine changes in the retina of the eye under the influence of $\mathrm{Cr}(\mathrm{VI})$, taking into account the fact that the optic nerve is formed by axons of cells whose bodies are located in the ganglion layer of the retina.

\section{Conclusions}

1. Our study provides an insight into the significant difference in the immunoreactivity of heat shock proteins of the HSP70 and HSP90 $\alpha$ families in neuroglia and endothelial cells of the optic nerve capillaries under the influence of $\mathrm{Cr}(\mathrm{VI})$. 
2. The results obtained suggest that $\mathrm{Cr}$ (VI) has a neurotoxic effect on the optic nerve with the development of edema, which is manifested by the thickening of nerve fibers. A comparison of the dynamics of the development of the dystrophic process in the optic nerve with the results of the immunohistochemical analysis showed, that an increase in the thickness of nerve fibers is accompanied by an increase in immunoreactive neuroglial cells (HSP90 $\alpha$ ) and endothelial cells (HSP70).

\section{Conflicts of interest}

The authors declare that they have no conflicts of interest.

\section{References}

[1] Kesler, A, Pianka, P. (2003). Toxic optic neuropathy. Current Neurology and Neuroscience Reports, 3 (5), 410-414. doi: http:// doi.org/10.1007/s11910-003-0024-y

[2] Sharma, R., Sharma, P. (2011). Toxic optic neuropathy. Indian Journal of Ophthalmology, 59 (2), 137-141. doi: http://doi.org/ 10.4103/0301-4738.77035

[3] Abri Aghdam, K., Zand, A., Soltan Sanjari, M. (2019). Bilateral Optic Disc Edema in a Patient with Lead Poisoning. Journal of ophthalmic \& vision research, 14 (4), 513-517. doi: http://doi.org/10.18502/jovr.v14i4.5465

[4] Tong, S., Li, H., Wang, L., Tudi, M., Yang, L. (2020). Concentration, Spatial Distribution, Contamination Degree and Human Health Risk Assessment of Heavy Metals in Urban Soils across China between 2003 and 2019 - A Systematic Review. International Journal of Environmental Research and Public Health, 17 (9), 3099. doi: http://doi.org/10.3390/ijerph17093099

[5] Tytła, M. (2019). Assessment of Heavy Metal Pollution and Potential Ecological Risk in Sewage Sludge from Municipal Wastewater Treatment Plant Located in the Most Industrialized Region in Poland - Case Study. International Journal of Environmental Research and Public Health, 16 (13), 2430. doi: http://doi.org/10.3390/ijerph16132430

[6] Sharma, P., Bihari, V., Agarwal, S. K., Verma, V., Kesavachandran, C. N., Pangtey, B. S. et. al. (2012). Groundwater Contaminated with Hexavalent Chromium [Cr (VI)]: A Health Survey and Clinical Examination of Community Inhabitants (Kanpur, India). PLoS ONE, 7 (10), e47877. doi: http://doi.org/10.1371/journal.pone.0047877

[7] Megremi, I., Vasilatos, C., Vassilakis, E., Economou-Eliopoulos, M. (2019). Spatial diversity of Cr distribution in soil and groundwater sites in relation with land use management in a Mediterranean region: The case of C. Evia and Assopos-Thiva Basins, Greece. Science of The Total Environment, 651, 656-667. doi: http://doi.org/10.1016/j.scitotenv.2018.09.186

[8] Doorn, P. F., Campbell, P. A., Worrall, J., Benya, P. D., McKellop, H. A., Amstutz, H. C. (1998). Metal wear particle characterization from metal on metal total hip replacements: transmission electron microscopy study of periprosthetic tissues and isolated particles. Journal of Biomedical Materials Research, 42 (1), 103-111. doi: http://doi.org/10.1002/ (sici)1097-4636(199810)42:1<103::aid-jbm13>3.0.co;2-m

[9] Catelas, I., Bobyn, J. D., Medley, J. B., Krygier, J. J., Zukor, D. J., Huk, O. L. (2003). Size, shape, and composition of wear particles from metal-metal hip simulator testing: Effects of alloy and number of loading cycles. Journal of Biomedical Materials Research, 67A (1), 312-327. doi: http://doi.org/10.1002/jbm.a.10088

[10] Mahendra, G., Pandit, H., Kliskey, K., Murray, D., Gill, H. S., Athanasou, N. (2009). Necrotic and inflammatory changes in metal-on-metal resurfacing hip arthroplasties. Acta Orthopaedica, 80 (6), 653-659. doi: http://doi.org/10.3109/17453670903473016

[11] Korovessis, P., Petsinis, G., Repanti, M., Repantis, T. (2006). Metallosis After Contemporary Metal-on-Metal Total Hip Arthroplasty. The Journal of Bone \& Joint Surgery, 88 (6), 1183-1191. doi: http://doi.org/10.2106/jbjs.d.02916

[12] Campbell, J. R., Estey, M. P. (2013). Metal release from hip prostheses: cobalt and chromium toxicity and the role of the clinical laboratory. Clinical Chemistry and Laboratory Medicine, 51 (1), 213-220. doi: http://doi.org/10.1515/cclm-2012-0492

[13] Mabilleau, G., Kwon, Y.-M., Pandit, H., Murray, D. W., Sabokbar, A. (2008). Metal-on-metal hip resurfacing arthroplasty: A review of periprosthetic biological reactions. Acta Orthopaedica, 79 (6), 734-747. doi: http://doi.org/10.1080/17453670810016795

[14] Iavicoli, I., Falcone, G., Alessandrelli, M., Cresti, R., De Santis, V., Salvatori, S. et. al. (2006). The release of metals from metal-on-metal surface arthroplasty of the hip. Journal of Trace Elements in Medicine and Biology, 20 (1), 25-31. doi: http:// doi.org/10.1016/j.jtemb.2005.10.002

[15] Apel, W., Stark, D., Stark, A., O'Hagan, S., Ling, J. (2012). Cobalt-chromium toxic retinopathy case study. Documenta Ophthalmologica, 126 (1), 69-78. doi: http://doi.org/10.1007/s10633-012-9356-8

[16] Ng, S., Ebneter, A., Gilhotra, J. (2013). Hip-implant related chorio-retinal cobalt toxicity. Indian Journal of Ophthalmology, 61 (1), 35-37. doi: http://doi.org/10.4103/0301-4738.105053

[17] Garcia, M. D., Hur, M., Chen, J. J., Bhatti, M. T. (2020). Cobalt toxic optic neuropathy and retinopathy: Case report and review of the literature. American Journal of Ophthalmology Case Reports, 17, 100606. doi: http://doi.org/10.1016/j.ajoc.2020.100606

[18] Liu, H., Chen, H., Jing, J., Ma, X. (2011). Cloning and characterization of the HSP90 beta gene from Tanichthys albonubes Lin (Cyprinidae): effect of copper and cadmium exposure. Fish Physiology and Biochemistry, 38 (3), 745-756. doi: http://doi.org/ 10.1007/s10695-011-9556-2 
[19] Nadeau, D., Corneau, S., Plante, I., Morrow, G., Tanguay, R. M. (2001). Evaluation for Hsp70 as a biomarker of effect of pollutants on the earthworm Lumbricus terrestris. Cell stress \& chaperones, 6 (2), 153-163. doi: http://doi.org/10.1379/ 1466-1268(2001)006<0153:efhaab $>2.0$. co; 2

[20] Pearl, L. H., Prodromou, C. (2006). Structure and Mechanism of the Hsp90 Molecular Chaperone Machinery. Annual Review of Biochemistry, 75 (1), 271-294. doi: http://doi.org/10.1146/annurev.biochem.75.103004.142738

[21] Chang, Y.-W., Sun, Y.-J., Wang, C., Hsiao, C.-D. (2008). Crystal Structures of the 70-kDa Heat Shock Proteins in Domain Disjoining Conformation. Journal of Biological Chemistry, 283 (22), 15502-15511. doi: http://doi.org/10.1074/jbc.m708992200

[22] Avdonin, P. P., Markitantova, Y. V., Poplinskaya, V. A., Grigoryan, E. N. (2013). Determination of mRNA-transcripts and heat shock proteins HSP70 and HSP90 in the retina of the adult Spanish Ribbed Newt Pleurodeles waltl. Biology Bulletin, 40 (4), 343-350. doi: http://doi.org/10.1134/s106235901304002x

[23] Tytell, M., Greenberg, S. G., Lasek, R. J. (1986). Heat shock-like protein is transferred from glia to axon. Brain Research, 363 (1), 161-164. doi: http://doi.org/10.1016/0006-8993(86)90671-2

[24] Nita, M., Grzybowski, A. (2016). The Role of the Reactive Oxygen Species and Oxidative Stress in the Pathomechanism of the Age-Related Ocular Diseases and Other Pathologies of the Anterior and Posterior Eye Segments in Adults. Oxidative Medicine and Cellular Longevity, 2016, 1-23. doi: http://doi.org/10.1155/2016/3164734

[25] Maresca, A., la Morgia, C., Caporali, L., Valentino, M. L., Carelli, V. (2013). The optic nerve: A “mito-window" on mitochondrial neurodegeneration. Molecular and Cellular Neuroscience, 55, 62-76. doi: http://doi.org/10.1016/j.mcn.2012.08.004

[26] Xiao, F., Li, Y., Dai, L., Deng, Y., Zou, Y., Li, P. (2012). Hexavalent chromium targets mitochondrial respiratory chain complex I to induce reactive oxygen species-dependent caspase-3 activation in L-02 hepatocytes. International Journal of Molecular Medicine, 30 (3), 629-635. doi: http://doi.org/10.3892/ijmm.2012.1031

[27] Mary Momo, C., Ferdinand, N., Omer Bebe, N., Alexane Marquise, M., Augustave, K., Bertin Narcisse, V. et. al. (2019). Oxidative Effects of Potassium Dichromate on Biochemical, Hematological Characteristics, and Hormonal Levels in Rabbit Doe (Oryctolagus cuniculus). Veterinary Sciences, 6 (1), 30. doi: http://doi.org/10.3390/vetsci6010030

[28] Bucio, L., García, C., Souza, V., Hernández, E., González, C., Betancourt, M., Gutiérrez-Ruiz, M. C. (1999). Uptake, cellular distribution and DNA damage produced by mercuric chloride in a human fetal hepatic cell line. Mutation Research/Fundamental and Molecular Mechanisms of Mutagenesis, 423 (1-2), 65-72. doi: http://doi.org/10.1016/s0027-5107(98)00226-7

[29] Castellino, N., Aloj, S. (1969). Intracellular distribution of lead in the liver and kidney of the rat. Occupational and Environmental Medicine, 26 (2), 139-143. doi: http://doi.org/10.1136/oem.26.2.139

[30] Bolaños, J. P., Almeida, A., Fernández, E., Medina, J. M., Land, J. M., Clark, J. B., Heales, S. J. R. (1997). Potential mechanisms for nitric oxide-mediated impairment of brain mitochondrial energy metabolism. Biochemical Society Transactions, 25 (3), 944-949. doi: http://doi.org/10.1042/bst0250944

[31] Pandey, P., Saleh, A., Nakazawa, A., Kumar, S., Srinivasula, S. M., Kumar, V., Weichselbaum, R., Nalin, C., Alnemri, E. S., Kufe, D., Kharbanda, S. (2000). Negative regulation of cytochrome c-mediated oligomerization of Apaf-1 and activation of procaspase-9 by heat shock protein 90. The EMBO journal, 19 (16), 4310-4322. doi: http://doi.org/10.1093/emboj/19.16.4310

[32] Gurbuxani, S., Schmitt, E., Cande, C., Parcellier, A., Hammann, A., Daugas, E. et. al. (2003). Heat shock protein 70 binding inhibits the nuclear import of apoptosis-inducing factor. Oncogene, 22 (43), 6669-6678. doi: http://doi.org/10.1038/sj.onc.1206794

[33] Cavalcante, G. C., Schaan, A. P., Cabral, G. F., Santana-da-Silva, M. N., Pinto, P., Vidal, A. F., Ribeiro-dos-Santos, Â. (2019). A Cell's Fate: An Overview of the Molecular Biology and Genetics of Apoptosis. International Journal of Molecular Sciences, 20 (17), 4133. doi: http://doi.org/10.3390/ijms20174133

[34] Zou, H., Henzel, W. J., Liu, X., Lutschg, A., Wang, X. (1997). Apaf-1, a Human Protein Homologous to C. elegans CED-4, Participates in Cytochrome c-Dependent Activation of Caspase-3. Cell, 90 (3), 405-413. doi: http://doi.org/10.1016/s0092-8674(00)80501-2

[35] Jedlicka, P., Mortin, M. A., Wu, C. (1997). Multiple functions of Drosophilaheat shock transcription factorin vivo. The EMBO Journal, 16 (9), 2452-2462. doi: http://doi.org/10.1093/emboj/16.9.2452

[36] Ali, A., Bharadwaj, S., O'Carroll, R., Ovsenek, N. (1998). HSP90 Interacts with and Regulates the Activity of Heat Shock Factor 1 in Xenopus Oocytes. Molecular and Cellular Biology, 18 (9), 4949-4960. doi: http://doi.org/10.1128/mcb.18.9.4949

[37] Dou, F., Chang, X., Ma, D. (2007). Hsp90 Maintains the Stability and Function of the Tau Phosphorylating Kinase GSK3 $\beta$. International Journal of Molecular Sciences, 8 (1), 51-60. doi: http://doi.org/10.3390/i8010060

[38] Zou, J., Guo, Y., Guettouche, T., Smith, D. F., Voellmy, R. (1998). Repression of Heat Shock Transcription Factor HSF1 Activation by HSP90 (HSP90 Complex) that Forms a Stress-Sensitive Complex with HSF1. Cell, 94 (4), 471-480. doi: http:/doi.org/ 10.1016/s0092-8674(00)81588-3

[39] Abravaya, K., Myers, M. P., Murphy, S. P., Morimoto, R. I. (1992). The human heat shock protein hsp70 interacts with HSF, the transcription factor that regulates heat shock gene expression. Genes \& Development, 6 (7), 1153-1164. doi: http:/doi.org/ 10.1101/gad.6.7.1153

[40] Schoof, N., von Bonin, F., Trümper, L., Kube, D. (2009). HSP90 is essential for Jak-STAT signaling in classical Hodgkin lymphoma cells. Cell Communication and Signaling, 7 (1). doi: http://doi.org/10.1186/1478-811x-7-17 
[41] Padmini, E., Usha Rani, M. (2011). Heat-shock protein 90 alpha (HSP90 $\alpha$ ) modulates signaling pathways towards tolerance of oxidative stress and enhanced survival of hepatocytes of Mugil cephalus. Cell Stress and Chaperones, 16 (4), $411-425$. doi: http://doi.org/10.1007/s12192-011-0255-9

[42] Bernstein, S. L., Russell, P., Wong, P., Fishelevich, R., Smith, L. E. (2001). Heat shock protein 90 in retinal ganglion cells: association with axonally transported proteins. Visual Neuroscience, 18 (3), 429-436. doi: http://doi.org/10.1017/s0952523801183094

[43] Ravagnan, L., Gurbuxani, S., Susin, S. A., Maisse, C., Daugas, E., Zamzami, N. et. al. (2001). Heat-shock protein 70 antagonizes apoptosis-inducing factor. Nature Cell Biology, 3 (9), 839-843. doi: http://doi.org/10.1038/ncb0901-839

[44] Lorenzo, H. K., Susin, S. A., Penninger, J., Kroemer, G. (1999). Apoptosis inducing factor (AIF): a phylogenetically old, caspase-independent effector of cell death. Cell Death \& Differentiation, 6 (6), 516-524. doi: http://doi.org/10.1038/ sj.cdd. 4400527

[45] Kondrikov, D., Fulton, D., Dong, Z., Su, Y. (2015). Heat Shock Protein 70 Prevents Hyperoxia-Induced Disruption of Lung Endothelial Barrier via Caspase-Dependent and AIF-Dependent Pathways. PLOS ONE, 10 (6), e0129343. doi: http://doi.org/ 10.1371/journal.pone.0129343

[46] Shivers, R. R., Pollock, M., Bowman, P. D., Atkinson, B. G. (1988). The effect of heat shock on primary cultures of brain capillary endothelium: inhibition of assembly of zonulae occludentes and the synthesis of heat-shock proteins. European Journal of Cell Biology, 46 (1), 181-195.

[47] Pournaras, C. J., Rungger-Brändle, E., Riva, C. E., Hardarson, S. H., Stefansson, E. (2008). Regulation of retinal blood flow in health and disease. Progress in Retinal and Eye Research, 27 (3), 284-330. doi: http://doi.org/10.1016/j.preteyeres.2008.02.002

[48] Doll, D. N., Hu, H., Sun, J., Lewis, S. E., Simpkins, J. W., Ren, X. (2015). Mitochondrial Crisis in Cerebrovascular Endothelial Cells Opens the Blood-Brain Barrier. Stroke, 46 (6), 1681-1689. doi: http://doi.org/10.1161/strokeaha.115.009099

[49] Connolly, N. M. C., Theurey, P., Adam-Vizi, V., Bazan, N. G., Bernardi, P., Bolaños, J. P. et. al. (2017). Guidelines on experimental methods to assess mitochondrial dysfunction in cellular models of neurodegenerative diseases. Cell Death \& Differentiation, 25 (3), 542-572. doi: http://doi.org/10.1038/s41418-017-0020-4

[50] Golpich, M., Amini, E., Mohamed, Z., Azman Ali, R., Mohamed Ibrahim, N., Ahmadiani, A. (2016). Mitochondrial Dysfunction and Biogenesis in Neurodegenerative diseases: Pathogenesis and Treatment. CNS Neuroscience \& Therapeutics, 23 (1), 5-22. doi: http://doi.org/10.1111/cns.12655 